\title{
Popular Recreational Games Effect on Some Social Skills and Behavioral Manifestations of Kindergartens
}

\author{
Mohamed Omar Abdulrasoul Abdulla ${ }^{1}$ \\ ${ }^{1}$ Lecturer at the Sports Recreational Department, Faculty of Physical Eduction for Girls, Alexandria University, Egypt
}

\begin{abstract}
Represents the interest of the study to assess the level of standard childhood growth and development of societies,It is in fact an interest in the future of the whole nation, where the number of children and their upbringing is preparing to face the challenges of civilization imposed inevitability ' And require proper planning educational process to study the laws governing the process of growth, as well as the factors that drive the growth and characteristics of any age can even explain the behavior and children's capabilities objectively evaluation.Childhood is the most important stages in human life at this stage featuring children's abilities and talents, bloom and be vulnerable and guidance to your child, the main feature is the tendency to play, through this natural tendency child learns through movement and grow his thinking and personality
\end{abstract}

\section{Introduction}

$\mathrm{R}$ epresents the interest of the study to assess the level of standard childhood growth and development of societies, It is in fact an interest in the future of the whole nation, where the number of children and their upbringing is preparing to face the challenges of civilization imposed inevitability ' And require proper planning educational process to study the laws governing the process of growth, as well as the factors that drive the growth and characteristics of any age can even explain the behavior and children's capabilities objectively evaluation.Childhood is the most important stages in human life at this stage featuring children's abilities and talents, bloom and be vulnerable and guidance to your child, the main feature is the tendency to play, through this natural tendency child learns through movement and grow his thinking and personality

Amin Al-kholi and Jamal El-Shafei, (2000)add that the school physical education curriculum offers colors of physical activities and experiences in middle of psychological and social values loom in biochemical interaction works with little guidance on the development of individual personality and he assumed that the individual finds meaning and significance through his participation in motor activity has focused on the meaning through the sense of fun and joy and satisfaction inherent in the activity and kinetic experiences in itself in addition to the educational experiences and activities achieve the desired outcomes by Pupils, as the calendar should not be limited on the side without the rest of the fundamental aspects of the curriculum and especially after becoming calendar tools available for such all aspects (Amin Al-kholi and Jamal El-Shafei 2000)

Gallehue (1990) sees that the selection of games for children of school age not inconsiderable task so it must be good thinking and planning when choosing the type of motor activity, which balanced growth of the child physically and mentally and psychologically and socially (Gallehue 1990)

Mohamed Allawi (1992)indicats that the children's movement featuring timely cruise and good movement of movement of the torso to the arms and feet are characterized as fast absorption and learning of good moves and the ability to harmonize different circumstances (Mohamed Allawi, 1992)

Betty et al (1997)confirm thatPrograms that rely on popular games improve the capacities of children (Beatty et al, 1997)

Mohamed Sultan s (2000) confirms that games performed by children are important and essential to 
their lives since the first years of age and is the basis for many activities (Mohamed Sultan, 2000

Mohamed OmarAbdelRasool Abdullah (2004) and Mohamed Adel Khattab (1964)reported that the popular games is the first aspects of human activity in childhood, is a mirror image reflection of life and childhood not without a history of a nation, the appearance of which must be available in every community, they expose the life forms in the environment with natures, traditions and its system, as it is simple and friendly to the same child, plus they don't require large areas of land, but it will be done Anywhere, it does not need the tools or devices so they are located at the front of the colors of the activity can be organized for children, as they are known, and pop with their preferences and traditions (Mohamed Omar Abdel Rasoul Abdullah, 2004) (Mohamed Adel Kattab 1964)

Each of SchopHozel (1993), Ali Mahmoud Al-Dairi (2001) which all indicated that popular games as a likable and interested for kids that is considered the best methods that can be used as an effective means of improving motor fluency (1 SchopHozel, 1993), Ali Mahmoud Al-Dairi, 2001)(

Each of Azza Abdel Fattah shimi (1995), Wahib Mohamed Labib (1998)agreed that, beloved children's play activities are popular games where you play a role in the transfer of the cultural heritage of the community of the child learns some social values leading to the development of social interaction and social relationships, which is reflected on the importance of child education and community life and selfisolationism and perhaps psychological feeling of loneliness, kids in public places and in the villages and places children according to their laws, so It is easy to perform for children (Azza Abdel Fattah shimi, 1995), (Wahib Mohamed Labib, 1998)

The most important thing about childhood is natural inclination to play and movement through this tendency child learns to practice and shrewd modern educators to the importance of play and movement during this stage and they find it an advantage of features that must be tapped and utilized in the process of education, where Mohamed Allawi (1992)indicates that the child's upbringing and development of their physical and mental capacities and psychological and social services whether in motion and granular activity to itself (Mohamed Allawi 1992)
Researcher finds that try behaviors of the child's behavior behavioral habits intact, replace it, it can use the popular recreational games to achieve this goal so popular recreational games are one of the areas that help build your child's personality, what gives him opportunities to express himself and his abilities and his creations, and it's a rich area activities that satisfy the child's need for urgent action and reflection and creativity, which acquired through exercising psychological and physiological fitness and skill,

This refers Mohamed Alhamahemy and Aida Abdel Aziz (1998) the recreation provided the child experiences and information by Auto (Mohamed Alhamahemy and Aida Abdel Aziz, 1998), add TahanyAbdelsalam $(2000 \mathrm{~m})$ recreational activities help to feel happiness and joy and pride to accomplish work (Tahany Abdel Salam (2000: 245) Proceeding from the fact that a lot of modern educational trends for treatment of problems facing children, stressed the importance of recreational exercise children preschool games in General, with the aim of identifying effective positively represented in the improvement of communicative and social skills development and behavioural manifestations (Berken, Shermer, 2001)

The researcher found that using popular recreational games which may modify the social skills and behavioral manifestations of kindergartens

\section{Study Objectives}

The current study aims to:

1- Recognizing the influence of popular recreational games in social skills and behavioral manifestations of kindergartens. about the influence of popular recreational games in social skills and behavioral manifestations of kindergartens

2- Recognizing differences between the two post measures for both of the control and experimental groups of popular recreational games in social skills and behavioral manifestations of kindergartens

\section{Hypothesis}

1- There is a significant statistical differences between the pre- post measurements with the experimental and control groups in social skills and behavioral manifestations favor to the post measure with kindergartens.

2- There is a significant statistical differences between the two pre- measurements with the experimental and 
control groups favor to the post measure with for the experimental group.

\section{Method}

The researcher utilized the experimental group because of its appropriated to the research nature in the experimental design image for one experimental group with using the pre-post measure.

\section{Sample}

The researcher chooses the sample in some way intentional sample of boys only school official languages AzzatZidane kindergarten in Fayoum,

The total number of major sample was (30) children, plus a number of (10) children from the same community to conduct scientific transactions for data collection tools.

Tools
Through the reference frame of the researcher in the study reached the following scales :

- Social skills Scale prepared by HaiamYakoutSotoohy 2005Annex(1)

- Behavioral manifestations review list scaleprepared by Nadia IbraheimAbdulkader (22) Annex (2)

\section{The sample uniformity}

The researcher has conducted measurements of variables (age, height, weight, social skills, behavioral manifestations) on a sample of(30) children, with to create uniformity among them before applying the major study

the table (1)shows the coefficient convolution of variables (age, height, weight, social skills, behavioral manifestations) ranged between (-0.46:-0.06) these values are limited between $( \pm 3)$ located under the equinoctial curve which shows the search sample smoothing

Table (1)

Uniformity of variables (age, height, weight, social skills, behavioral manifestations) $(n=30)$

\begin{tabular}{|c|c|c|c|c|}
\hline Variables & Mean & Standard Deviation & Median & Torsion \\
\hline Age & 4.93 & 2.16 & 5 & -0.09 \\
\hline height & 115.71 & 6.50 & 116 & $-0.13-$ \\
\hline Weight & 25.90 & 4.72 & 25 & -0.06 \\
\hline Social Skills & 9.25 & 2.85 & 12 & -0.46 \\
\hline $\begin{array}{c}\text { Behavioral } \\
\text { Manifestations }\end{array}$ & 11.70 & 1.95 & 9 & 26 \\
\hline
\end{tabular}

The Parity

The researcher carried out the pre- measures for the (control\& experimental )groups in a( social skills , behavioral manifestations test)to find parity between(control \& experimental )groups ,he clarified that there is no significant statistical differences between the pre-post measurements for the (control\& experimental )groups in a( social skills , behavioral manifestations)under discussion, which prove the parity between the two groups in the variables under discussion.

Table (2)

Differences between Pre-Post Measures with the control \& experimental groups in (social skills- Behavioral manifestations) under discussion $\mathrm{T}$ Test $(\mathrm{N} 1=\mathrm{n} 2=15)$

\begin{tabular}{|c|c|c|c|c|c|c|}
\hline \multirow{2}{*}{$\begin{array}{c}\begin{array}{c}\text { Statistical } \\
\text { transactions }\end{array} \\
\text { Dimensions }\end{array}$} & \multicolumn{2}{|c|}{$\overline{\text { Control group }}$} & \multicolumn{2}{|c|}{ Experimental group } & \multirow{2}{*}{$\begin{array}{l}\text { Difference } \\
\text { between the } \\
\text { two means }\end{array}$} & \multirow{2}{*}{ T Value } \\
\hline & S/ & $+\mathbf{A}$ & S/ & $+\mathbf{A}$ & & \\
\hline Social skills & 9.24 & 1.11 & 9.25 & 1.21 & 0.01 & 0.02 \\
\hline $\begin{array}{c}\text { Behavioral } \\
\text { manifestation }\end{array}$ & 10.41 & 1.35 & 10.39 & 1.22 & 0.02 & 0.03 \\
\hline
\end{tabular}

*T Value with $0.05=2.045$ 


\section{Popular Games Program:}

\section{The program aim:}

The program aims to improve sense-motor perception with children under discussion, in addition to enjoy, interest, motivation to perform motor activity.

\section{Time plan:}

The program included (8) weeks (3) units per week (Sunday, Tuesday, Thursday) time unit (45) precise hacker activity hour (Break) and within the schedule of the experimental schools, researcher may sponsor unit time distribution is as follows

$*(5 \mathrm{~m})$ warm up, $*(35 \mathrm{~m})$ popular games, $*(5 \mathrm{~m})$ Calming exercises

The major study:
First :pre-post measures

The researcher has conducted pre-measure for the two research groups(control\&experimental)in 8/10/2015, the post measure in $7 / 12 / 2015$.

Second: Experiment application: researcher popular games program on experimental group (2), while traditional games were applied to the control group, from $11 / 10 / 2015$ to $6 / 12 / 2015$

\section{Results}

Results was displayed according o the statistical used method

Table (3)shows that there is a significant statistical differences between pre-post measures with thecontrol group in the (social skills- behavioral manifestations) under discussion favor to the post -measure.

Table (3)

Shows that there is a significant statistical differences between pre-post measures with the control group in the (social skills- behavioral manifestations) underdiscussion with $T$ Test $(N=15)$

\begin{tabular}{|c|c|c|c|c|c|c|}
\hline \multirow{2}{*}{$\begin{array}{c}\begin{array}{c}\text { Statistical } \\
\text { transactions }\end{array} \\
\text { Dimensions }\end{array}$} & \multicolumn{2}{|c|}{ Pre-measure } & \multicolumn{2}{|c|}{ Post- measure } & \multirow{2}{*}{$\begin{array}{l}\text { Difference } \\
\text { between the } \\
\text { two means }\end{array}$} & \multirow{2}{*}{ T Value } \\
\hline & S/ & $+\mathbf{A}$ & S/ & $+\mathrm{A}$ & & \\
\hline Social skills & 9.24 & 1.11 & 12.14 & 1.32 & 2.9 & $8.06^{*}$ \\
\hline $\begin{array}{c}\text { Behavioral } \\
\text { manifestation }\end{array}$ & 10.41 & 1.35 & 13.14 & 1.15 & 2.73 & $8.53^{*}$ \\
\hline
\end{tabular}

*T Table value with $0.05=2.045$

Table (4) shows that there is a significant statistical differences between the two pot -measures for the control \&experimental groups in social skills and behavioral manifestations under discussion favor o the post -measure of the experimental group

Table (4)

Differences between the pre-post measures for the experimental group with the social skills and behavioral manifestations under discussion with $T$ Test $(N=15)$

\begin{tabular}{|c|c|c|c|c|c|c|}
\hline \multirow{2}{*}{$\begin{array}{c}\begin{array}{c}\text { Statistical } \\
\text { transactions }\end{array} \\
\text { Dimensions }\end{array}$} & \multicolumn{2}{|c|}{ Pre-measurf } & \multicolumn{2}{|c|}{ Post- measure } & \multirow{2}{*}{$\begin{array}{l}\text { Difference } \\
\text { between the } \\
\text { two means }\end{array}$} & \multirow{2}{*}{ T Value } \\
\hline & S/ & $+\mathbf{A}$ & S/ & $+\mathbf{A}$ & & \\
\hline Social skills & 9.25 & 1.21 & 17.69 & 1.28 & 8.44 & $17.96 *$ \\
\hline $\begin{array}{c}\text { Behavioral } \\
\text { manifestation }\end{array}$ & 10.39 & 1.22 & 13.24 & 1.27 & 7.85 & $16.70^{*}$ \\
\hline
\end{tabular}

*T Table value with $0.05=2.045$

Table (5) shows that there is a significant statistical differences between the two pot-measures for the control \&experimental groups in social skills and behavioral manifestations under discussion favor o the post-measure of the experimental group 
Table (5)

The differences between the two pot -measures for the control \&experimental groups in social skills and behavioral manifestations under discussion with $T$ Test $(\mathrm{N} 1=\mathrm{n} 2=15)$

\begin{tabular}{|c|c|c|c|c|c|c|}
\hline \multirow{2}{*}{$\begin{array}{c}\begin{array}{c}\text { Statistical } \\
\text { transactions }\end{array} \\
\text { Dimensions }\end{array}$} & \multicolumn{2}{|c|}{ Control group } & \multicolumn{2}{|c|}{ Experimental group } & \multirow{2}{*}{$\begin{array}{l}\text { Difference } \\
\text { between the } \\
\text { two means }\end{array}$} & \multirow{2}{*}{ T Value } \\
\hline & S/ & $+\mathbf{A}$ & $\mathbf{S} /$ & $+\mathbf{A}$ & & \\
\hline Social skills & 12.14 & 1.32 & 17.69 & 1.28 & 5.55 & $11.33 *$ \\
\hline $\begin{array}{c}\text { Behavioral } \\
\text { manifestation }\end{array}$ & 13.1 & 1.15 & 18.24 & 1.27 & 5.10 & $11.09 *$ \\
\hline
\end{tabular}

*T Table value with $0.05=2.045$

\section{Results}

Table $(3,4)$ shows that shows that there is a significant statistical differences between the two pot -measures for the control \&experimental groups in social skills and behavioral manifestations under discussion favor to the post measure.

These results are due to the positive impact of popular recreational games on social skills and behavioral manifestations of kindergartens has popular games interesting movements and attractive recreational taken in its changing conditions both on the ground and in the air in addition to distinguish movements and body positions require a high degree of control in all its parts making the kids have the ability and discrimination and identify all parts of the body and the distances and heights and different weights and thereby increase their ability to deal with society.

These results are consistent with the results of the study hopes Morsi, Maha Al-Attar (2000 m) (3) that a programme of popular recreational games positive impact on the social development of children (AmalMorsi, Maha Al-Attar: (2000)

The researcher attributed this result to the popular recreational games where the spirit of cooperation and teamwork and the thrill is climate helps them to connect and communicate between children and active participation in the activity leading to add successful social relationships with them through the development of the abilities and aptitudes of those children as far as possible, and moral stimulation method for children, which included popular games, this is consistent with the indicated "AmalMorsi, Maha Al-Attar "(2000) to train children to some social skills and social interaction through cooperation and teamwork and helping the needy and exchange of give and take, not only training but some leisure activities and intramural sports,
That have the greatest impact on what happens on the level of social interactions of marked improvement (AmalMorsi, Maha Al-Attar, 2000)(

This is consistent with the indicated Mahmoud Hammouda (2005) that the child's behavior when he's in the wrong position and place (AmalMorsi, Maha AlAttar, 2000 m), as well as beer "Joseph Pear" (1999) to guided steps for its mainstream behavioral change and interest in promoting normal behavior immediately after its occurrence and triggered from the results that lead to the likelihood of occurrence, and the scaffolding necessary to activate and pay negative,lazy child to be involved in the popular recreational games (Joseph Pear, 1999) : $174 .($

As you can see, "Nadia Ibrahim Abdel Kader Abu Saud (2002) disturbance of behavior is the cry of the child to seek help for psychological difficulty experienced by the child and this difficulty as a result of his inability to connect with others, and shortcomings and failures in developing emotional and emotional relationships with others and the automatic repetition of words, inertia meaning maintaining the same things, monotonous repetition of acts and words (Nadia Ibrahim Abdel Kader Abu Saud, 2002)

Table (5)shows that here is a significant statistical differences between the two post measures for the experimental \&control groups in the social skills, behavioral manifestations under discussion favor to post measure for the experimental group ,the popular games applied on the experimental group has a better positive effect than the traditional applied game on the control group.

The researcher attributed this result to the popular recreational games used in partial imitation games are important for some animals, however, agree with Sigel pointed out (1996) to the tradition of doing the body without using nothing but refer, for example, is a form 
of physical tradition, but continuing training the child can imitate some signals, movements Sigel 1996)(

As a stone (Ston, et al) (1997) that kindergartens have low skills and especially kinetic tradition $\mathrm{t}$ and training intervention impact well in improving this skill of these children (Ston, et al), (1997), this is also confirmed by the study of McDonovgh (1997) that the tradition is the first skill in communication and kindergartens suffer from failure at this point but through improved training intervention or shows these children significantly in Imitate certain acts or Naturals no improvement in communication skills McDonovgh, 1997)

As Hassan Abdel moaty (2003) behavioral therapy designed to modify the behavior of unwanted children (burst), and often uses positive reinforcement method and means to reward the child after the desired behavior, and rehearse material strengthening via money or candy, moral may be kissing the child or pet him or praise or thanks (Hassan Abdel moaty, 2003)

These results have agreed with AdilAbd Allah (2000) which revealed how effective training program for the development of communication skills on some behavioral manifestations and positive results in terms of lower activity level overload with its dimensions (Adel Abdul-Allah, 2000)

This achieves search assumptions

\section{Conclusions}

* The popular recreational games have a positive effect on the development of social skills in kindergarten.

* Popular recreational games have a positive effect on the development of behavioral manifestations in kindergarten

\section{Recommendations}

*Use popular games recreational social skills development in kindergarten.

* Popular recreational games in refining the behavioral manifestations of kindergartens.

* Carry out Similar studies to identify the impact of recreation on the popular games of different categories of children

\section{References}

\section{Arabic references}

1- Amal Morsi, Maha Al-Attar: (2000) "the influence of popular games on kinetic fitness and reduce loneliness for mentally handicapped children, the third Scientific Conference, Faculty of physical education for girls, Aljazira, October.

.2- Amin Anwar kholi, Jamaluddin Al-shaafa'i: (2000), physical education curricula in contemporary Dar AlfekrAlaraby,Cairo. 67, 177, 372, 484

3- Tahany Abdel salam Mohamed: foundations of recreation and respite

education, Dar AlfekrAlaraby, Cairo, 2001. 245

4- Hassan Mustafa Abdul-Mu'ti (2003): mental disorders in childhood and adolescence (causesdiagnosis-treatment), Dar Alkahera, Cairo .259

5- Adel Abd Allah Mohamed (2000): some social behavioral performance patterns of autistic children and their peers mentally, Journal of the Faculty of education, University, number 35 , pp $9-35$

6- Azza Abdel Fattah shimi: (1995), "the impact of a proposed programme for small toys to perform some offensive skills in basketball for the mentally retarded," scientific journal specializing in the science of physical education, faculty of sport education for Men, (24), Alexandria. 60

8- Ali Mahmoud Al-Dairi: (2001), effective teaching using the problem solving teaching method to improve some skills of basic school students basketball, international scientific conference sport and globalization, Faculty of physical education for Men, Helwan University.

9- Mohamed Ibrahim Sultan: (2000), "basic motor skills as an indicator to start practicing and teaching some basic skills in football (follow up study)," scientific journal of physical education and sports, physical education for Men, Alexandria University 115.

10- Aida Abdul Aziz Mohamed,: recreation between theory and practice, MarkazAlketab for publishing, Cairo, 1998. 160

11- Mohamed Hassan Allawi: (1992), the science of sports training, I 12, Dar almaaref, Cairo. 15, 65.

12- Mohamed Omar Abdel Rasoul Abdullah (2004) the role of popular games in sports for all activation 
programs in youth centers in Fayoum governorate, unpublished thesis, Faculty of physical education for Men,

Helwan University

13- Mahmoud Hamza(2005)

Childhood and adolescence and psychological therapy, MatbaaAlfan Cairo, 131

14- Nadia Ibrahim Abdel Kader Abu Saud (2002): effective use of cognitive behavioral therapy program in the development of emotions, Autistic children and their parents, $\mathrm{PhD}$, psychosocial studies, Graduate Institute of childhood, Ain Shams University. 84-88

15- Haiam YakoutSotoohy 2005: the effectiveness of a proposed program me for integration between kindergarten and the family in the development of social skills for kindergarten, Master thesis, Institute of pedagogical studies and research, University of Cairo

16- Wahib Mohamed Labib: (1998), "popular games and its role in the child's upbringing in age (6-12) years - a field study of some villages in the Eastern Province", unpublished PhD thesis, Graduate Institute of Arts, Academy of Arts 8, 9Berken ,Shermer : (2001) In Tegrating Physical Education to Teach Appropriate Play Skills To Learners With Autism, Adapted Physical Activity Quarterly Champaign , J11., 5 , Jul .65,.

\section{English references:}

17- Betty,J.\& others (1997), Physicl education unit plans for pre-school kinder garden learning experience in games, gymnastics and dance, Human Kineties, U.S.A .

18- Gallahue, D. (1990),Understanding motor development in children, New York, John Wiley \& Sons. 19

19- Joseph , Pear \& Garry Martin :(1999), Behavior Modification, What is and How to do it, Prentice Hall, Upper, Saddle River, New Jersery 074538. .174

20- Mcdonough - L \&Stahmer - A \&Scheribman -L \&Thampsam - SJ. Deficits, delays, and distractions; an evaluation of symbolic play and memory in children with autism, Dev- Psychopath ol, (1) P.P. 17 - 41, 1997.

21- Schoop, P.\&Hozel, D. (1993), Early childhood curricu-lum New York, MacMillan Pub. Company .

22- Sigel ,Brany : (1996) The Autistic Children Understanding and Treating Autistic Spectrum Disorders, Oxford University Press, U.S.A,.38

23- Stone - Wl, \&Ousleyoy\&Littleford - CD, Motor imitation in young children with autism : (1997), What's the object? J. Abnormal - Child - Psycho, v25 (6) P.P. $415: 85$. 